\title{
»Reducing Crime and Promoting Justice - Challenges to science, policy and practice«
}

\section{- Ein Tagungsbericht}

Joachim Kersten

\author{
13. Weltkongress für Kriminologie (»Reducing Crime and Promoting Justice - Challenges to science, policy and practice«) \\ der Internationalen Gesellschaft für Kriminologie in Rio de Janeiro/Brasilien vom 10. bis 15. August 2003
}

$\mathrm{D}$ er Kongress wurde am Abend des 10. August im Teatro Municipal in der Innenstadt von Rio feierlich eröffnet. Zahlreiche Persönlichkeiten aus der brasilianischen Politik, Gerichtsbarkeit und Kriminologie richteten ihre Grußadressen vom Podium an die versammelten Teilnehmer und Teilnehmerinnen. Die für westliche Wissenschaftler etwas ungewohnte Grandiosität dieser Veranstaltung (Gesangsvorführung samt Nationalhymne durch Knabenchor, rituelle/titelreiche Form der Wortbeiträge, Tanzvorführung am Abschluss der Feier) gab gewissermaßen einen Vorgeschmack auf die Andersartigkeit - wiederum aus westlicher Perspektive - dieses ersten Weltkongresses der internationalen Kriminologie auf dem lateinamerikanischen Kontinent.

Die wissenschaftlichen Beiträge wurden $a b$ Montag, dem 11. August im Kongresszentrum (Veranstaltungsort der Rio-Umweltkonferenz), zunächst auf einer Podiumsveranstaltung, ab dem Nachmittag auch in den Workshops zu fast 30 Themenbereichen der kriminologischen Forschung vorgetragen und diskutiert. Die zahlenmäßig größte Gruppe von Workshops hätte in der Sektion »Police Research and Practice« stattfinden sollen. Das für dieses Thema zuständige Mitglied des Organisationskomitees, Wesley Skogan von der Northwestern University, teilte uns während des Empfangs nach der Eröffnungszeremonie mit, dass mehr als 40\%, vielleicht sogar die Hälfte der im vorletzten Programmentwurf aufgeführten Teilnehmer nicht erschienen sei. Mein Eindruck war, dass in den anderen Themenbereichen die Ausfallquote teilweise noch höher zu veranschlagen war. Aufgrund der Absagen von Teilnehmern aus den USA und aus Westeuropa litt die Organisation der Workshop Sessions unter einem strukturellen Problem, das durch das Improvisationstalent der Veranstalter nur zum Teil ausgeglichen werden konnte.

Das Interesse an Workshops beispielsweise zu Themen wie Polizeikorruption, Restorative Justice u. Ä. war im Rahmen der insgesamt nicht überwältigenden Teilnehmerzahlen in den internationalen Workshops überschaubar. Allerdings diskutierten die erschienenen Wissenschaftler ausführlich über die vorgestellten Daten und Thesen.

Der diesjährige Kongress legte durch die Abwesenheit zahlreicher noch in der Endfassung des Programms aufgeführter Kollegen und Kolleginnen ein bemerkenswertes Phänomen bei Kriminologen offen, das bisher noch nicht so deutlich zutage getreten war: ihre doch wohl erhebliche Kriminalitätsangst. Auf mehrere Nachfragen hin erfuhr man von den Organisatoren, dass ein bekannter Kriminologe (der momentan in Neuseeland lehrt) in Bolivien von Mitgliedern einer kriminellen Gang entführt und als Geisel festgehalten worden sei. Dies habe vielen ansonsten doch sehr reiselustigen Vertretern der kriminologischen Zunft zu denken gegeben. Obwohl Bolivien und Brasilien einigermaßen unterschiedliche Länder sind (in

Europa würde man wegen einer Entführung auf Sardinien wohl kaum von einer Reise nach Frankreich absehen), hatte die Verbreitung der Nachricht über die Geiselnahme eine Welle von Entscheidungen geführt, dem Kongress in letzter Minute, teilweise auch ohne Absage, fernzubleiben. Es gäbe "Sicherheitsbedenken «, so einer der bekannteren deutschen Polizeiforscher. Mit Ausnahme eines tapferen Emeritus aus dem
Westfälischen und einer jungen Forscherin aus dem Max-Planck-Institut konnte man keine Vertreter der deutschen Universitätskriminologie entdecken.

Was steckt hinter dieser offenbar erheblichen Kriminalitätsfurcht? Was bedeutet es für den Ruf einer akademischen Disziplin, wenn deren Vetreter Angst vor dem eigenen Untersuchungsgegenstand haben? Man stelle sich einen Weltkongress der Immunologie, sagen wir in Norwegen vor, zu dem die Medizinprofessoren nicht erscheinen, weil sie sich wegen des kalten Klimas zu sehr vor Erkältungen fürchten.

Bei zahlreichen internationalen Teilnehmern stieß man auf verhaltene, zum Teil auch vernehmliche Kritik an der Organisation des Kongresses. Allerdings gab es auch ein paar aus dem Ausland angereiste Wissenschaftler und Wissenschaftlerinnen, die die Gelegenheit nutzen

Würde jemand in Europa eine Reise nach Frankreich unterlassen wegen einer Entführung in Sardinien? Was soll man von einer akademischen Disziplin halten, deren Vertreter so viel Berührungsamgst mit ihrem Gegenstand haben?

konnten, sowohl während des Kongresses als auch bei Unternehmungen am Kongressort, etwas über Land, Leute und die anstehenden sozialen Probleme in Brasilien und Lateinamerika zu erfahren. Zum Opfer von Kriminalität wurde meines Wissens nur ein Teilnehmer, dem abends am Strand der Copacabana die Brieftasche abhanden kam. Nähere Tatumstände wurden nicht bekannt. 